\title{
Correlações epigenéticas do câncer de boca e da doença periodontal
}

\begin{abstract}
- Amanda Hastenreiter Costa Dornelas Faculdade de Odontologia, Universidade Federal de Juiz de Fora (UFJF), Juiz de Fora, MG, Brasil • Karla de Andrade Luiz Faculdade de Odontologia, Universidade Federal de Juiz de Fora (UFJF), Juiz de Fora, MG, Brasil • Victória Boechat Feyo Faculdade de Odontologia, Universidade Federal de Juiz de Fora (UFJF), Juiz de Fora, MG, Brasil • Yuri de Lima Medeiros Faculdade de Odontologia, Universidade Federal de Juiz de Fora (UFJF), Juiz de Fora, MG, Brasil • Ana Carolina Alves Pereira Faculdade de Odontologia, Universidade Federal de Juiz de Fora (UFJF), Juiz de Fora, MG, Brasil • Raissa Caputo de Azevedo Faculdade de Odontologia, Universidade Federal de Juiz de Fora (UFJF), Juiz de Fora, MG, Brasil - Gisele Maria Campos Fabri Faculdade de Odontologia, Universidade Federal de Juiz de Fora (UFJF), Juiz de Fora, MG, Brasil
\end{abstract}

RESUMO | O objetivo deste artigo foi revisar a literatura em busca de possíveis inter-relações entre as alterações epigenéticas no câncer e na doença periodontal, alertando sobre uma potencial plausibilidade biológica. Para isso, realizou-se uma revisão narrativa da literatura por meio de uma pesquisa nas bases de dados LILACS, PubMed e SciELO pelos descritores "Epigenetic AND Periodontal disease”, "Epigenetic AND Oral cancer", e "Epigenetic AND Periodontal disease AND Oral cancer”. A partir dessa busca, foram selecionados 56 artigos sobre o tema. As evidências científicas demonstram que a inflamação crônica ocasionada pela presença das bactérias periodontopatogênicas no biofilme dental é capaz de produzir modificações epigenéticas, como metilação do DNA e modificações de histonas. Essas alterações podem inibir genes supressores de tumor e ativar oncogenes, que contribuem para o desenvolvimento e a progressão do câncer de boca. Portanto, há indícios de que o mecanismo fisiopatológico envolvido nas alterações epigenéticas no câncer e na doença periodontal são semelhantes. Conclui-se que existe uma relação positiva entre essas duas doenças, sugerindo que a doença periodontal pode ser um potencial fator de risco para o câncer de boca.

DESCRITORES | Doença Periodontal; Carcinoma Oral de Células Escamosas; Câncer; Epigenética; Metilação; Histona

ABSTRACT | Epigenetic correlations of oral cancer and periodontal disease - This study aimed to understand the association between epigenetic alterations in cancer and periodontal disease, verifying a potential biological plausibility. To this end, a narrative literature review was conducted in the LILACS, PubMed and SciELO databases for the descriptors "Epigenetic AND Periodontal disease," “Epigenetic AND Oral cancer," and “Epigenetic AND Periodontal disease AND Oral cancer”. The search returned 56 articles. Scientific evidence shows that chronic inflammation resulting from the presence of periodontopathogenic bacteria in the dental biofilm can lead to epigenetic modifications such as DNA methylation and histone. These changes can inhibit tumor suppressor genes and activate oncogenes, contributing to the development and progression of oral cancer. This indicates that epigenetic modifications in cancer and periodontal disease present similar pathophysiological mechanisms, thus pointing to a positive association between these two diseases and suggesting that periodontal disease may be a potential risk factor for oral cancer.

DESCRIPTORS | Periodontal Disease; Oral Squamous Cells Carcinoma; Cancer; Epigenetics; Methylation; Histone.

AUTOR CORRESPONDENTE
Gisele Maria Campos Fabri Departamento de Clínica Odontológica, Faculdade de Odontologia, Universidade Federal de Juiz de Fora • R. José Lourenço Kelmer s/n Juiz de Fora, MG, Brasil • 36036-900 E-mail: gisele.fabri@ufjf. edu.br

- Recebido 30 junho, 2021 • Aceito 31 agosto, 2021 


\section{INTRODUÇÃO}

A doença periodontal possui etiologia multifatorial, desencadeada por uma infecção de microrganismos da cavidade bucal como Porphyromonas gingivalis, Tannerella forsythia e Aggregatibacter actinomycetemcomitans. ${ }^{1-3} \mathrm{~A}$ doença inclui quadros de gengivite, caracterizados pela inflamação e sangramento da gengiva, e de periodontite, marcados pela formação de bolsas periodontais, recessão gengival, destruição tecidual e reabsorção óssea alveolar, podendo levar à perda dentária. ${ }^{4}$ Muitas vezes, a doença periodontal é insidiosa e subdiagnosticada, o que acarreta seu agravamento. Por ser um foco infeccioso crônico, pode causar bacteremia e alterações imunológicas importantes, com repercussão sistêmica. ${ }^{5-7}$

De acordo com o Instituto Nacional de Câncer, ${ }^{8}$ no Brasil, estima-se que são esperados 11.180 novos casos de câncer de boca em homens e 4.010 em mulheres para cada ano do triênio 20202022. A carcinogênese é um processo complexo em que as células envolvidas acumulam mutações em seu material genético, alterando, assim, o funcionamento da célula. Algumas dessas alterações não são modificações na sequência de DNA, sendo caracterizadas como eventos epigenéticos. ${ }^{9}$ As alterações epigenéticas foram relatadas em casos de lesões malignas e potencialmente malignas, sugerindo que essas alterações podem ser cruciais para o início da carcinogênese oral.9,10

As evidências científicas indicam uma associação entre infecções crônicas, inflamação e câncer. ${ }^{11-15}$ Mediadores de inflamação são constituintes importantes do ambiente local dos tumores. Em alguns tipos de câncer, é possível observar a presença de estados inflamatórios crônicos antes de ocorrer a transformação maligna. ${ }^{12}$

Assim, vários estudos relatam a relação entre doença periodontal e câncer bucal. ${ }^{2,3,16-18} \mathrm{~A}$ persistente produção e liberação de citocinas, fatores de crescimento e outros sinalizadores propiciam um ambiente favorável ao acúmulo de mutações das células epiteliais..$^{16,19,20}$ Esse acúmulo de fatores inflamatórios tem a capacidade de promover a proliferação celular, a sobrevivência dessas células por meio da ativação de oncogenes e a inativação de genes supressores de tumores ${ }^{15,16}$ que podem ocorrer por meio de alterações epigenéticas..$^{9,15,21}$

A epigenética consiste em alterações nos padrões de expressão gênica que não envolvem mudanças na sequência do DNA. ${ }^{22-24}$ Os eventos epigenéticos causam a remodelação da cromatina e a consequente ativação ou inativação de genes, o que determina a expressão gênica. ${ }^{1,22,24}$ Assim, os genes podem ser silenciados ou expressados ao longo do tempo. ${ }^{1,24}$ Essas alterações têm potencial de reversibilidade e podem ser transitórias. ${ }^{25}$

A metilação do DNA e as modificações de histonas são os principais mecanismos das alterações epigenéticas observados nas células humanas. ${ }^{22,23} \mathrm{~A}$ metilação é um mecanismo epigenético que consiste na adição de grupamentos metila à base citosina (C) do DNA, catalisada por enzimas. ${ }^{1,22,24}$ Já a deacetilação das histonas é um processo em que ocorre a remoção de um grupo acetila de uma histona, acarretando uma alteração da carga e o empacotamento do DNA, inibindo a transcrição gênica. ${ }^{1,26}$ Assim, ocorre o silenciamento de genes, que pode ser útil como biomarcador em carcinomas de células escamosas bucais. Dessa forma, a metilação de muitos genes supressores de tumor tem sido relatada em casos de câncer de boca. ${ }^{9,10,22}$

Sendo o câncer bucal o sexto câncer mais frequente em todo o mundo, ${ }^{23,27}$ estudos sobre as alterações nos padrões de expressão gênica na carcinogênese desse tipo de câncer são essenciais para fundamentar pesquisas e estratégias de prevenção. Portanto, o objetivo deste estudo foi realizar uma revisão narrativa da literatura sobre as possíveis inter-relações entre as alterações epigenéticas na doença periodontal e no câncer de boca, procurando verificar uma potencial plausibilidade biológica. 


\section{METODOLOGIA}

Realizou-se uma revisão narrativa da literatura mediante uma busca por artigos em inglês e espanhol, indexados nas bases de dados LILACS, PubMed e SciELO durante o período de janeiro de 2000 a maio de 2021. Para isso, empregouse, de forma combinada, as seguintes estratégias de pesquisa pelos descritores: "Epigenetic AND Periodontal disease", "Epigenetic AND Oral cancer" e "Epigenetic AND Periodontal disease AND Oral cancer". Também foram feitas buscas a partir das referências bibliográficas dos trabalhos selecionados.

Foram selecionados somente artigos relacionados à epigenética da doença periodontal e câncer de boca, de acordo com os títulos e resumos. Excluíram-se artigos em que o resumo apresentava acesso restrito, ou resumo com acesso disponível, mas artigo restrito. Além disso, foram desconsiderados comentários, editoriais, cartas, diretrizes das sociedades médicas e artigos que não apresentaram relação com o tema do manuscrito.

\section{REVISÃO DE LITERATURA Alterações epigenéticas na doença periodontal}

Alguns estudos têm demonstrado que as respostas inflamatórias e o sistema imunológico são altamente dependentes das alterações epigenéticas e podem ser determinantes na progressão da doença periodontal. ${ }^{16,28,29}$ Além disso, as bactérias relacionadas à doença periodontal apresentam potencial para causar alterações no estado de metilação do DNA. ${ }^{30,31}$ A presença de patógenos no biofilme dental e seus produtos, como os lipopolissacarídeos (LPS), provoca uma resposta inflamatória com produção de biomoléculas mediadoras de inflamação, como as citocinas (proteínas que exercem papel de mensageiros químicos), modulando a inflamação. Já foi comprovado que alterações epigenéticas nos genes codificadores de citocinas podem alterar sua expressão, bem como que alterações epigenéticas responsáveis por exacerbar a resposta inflamatória estão relacionadas com a periodontite. ${ }^{16,24,29,32}$

A disbiose responsável pelo desencadeamento da doença periodontal pode causar alterações epigenéticas, incluindo a acetilação de histonas e a modificação negativa da enzima DNA metiltransferase 1 (DNMT1). Além disso, a exposição de células epiteliais bucais e fibroblastos gengivais a bactérias periodontopatogênicas e lipopolissacarídeos in vitro resultou em modificações de histonas e hipermetilação dos genes. ${ }^{16,33}$

Pacientes com sangramento gengival grave e bolsas periodontais profundas apresentam aumento significativo na concentração de interferon gama (INF- $\gamma$ ) quando comparado a pacientes sem bolsas periodontais. ${ }^{32,34} \mathrm{O}$ INF- $\gamma$ participa da resposta inflamatória aguda e crônica, atraindo macrófagos e aumentando o número de células fagocitárias. Esta maior concentração de INF- $\gamma$ pode ser explicada através da hipometilação na região promotora dos genes que codificam a expressão desta citocina na doença periodontal. ${ }^{2}$

$\mathrm{O}$ fator de necrose tumoral alfa (TNF- $\alpha$ ) é outro mediador inflamatório produzido durante a resposta imune inata contra os patógenos periodontais. Ele é capaz de sustentar ou aumentar a inflamação através da indução da ativação de uma cascata molecular que induz a produção de mediadores secundários de inflamação, como a ciclooxigenase-2 (COX-2) e metaloproteínases de matriz. ${ }^{35}$ Os níveis de TNF- $\alpha$ no fluido crevicular gengival em pacientes com periodontite aguda são mais elevados que em pacientes com periodontite crônica. ${ }^{36}$ Interessantemente, níveis de hipermetilação no gene promotor de TNF- $\alpha$ estavam elevados em pacientes com doença periodontal crônica, o que causa o silenciamento do gene e a consequente diminuição da expressão de TNF- $\alpha$ nessa situação. ${ }^{16,35}$

Outras citocinas que participam da doença periodontal foram estudadas com relação a alterações 
epigenéticas e suas manifestações. Os genes promotores de interleucina-6 (IL-6), interleucina-8 (IL-8), e INF- $\gamma$ encontravam-se hipometilados em células epiteliais gengivais de pacientes com periodontite, quando comparados com controles saudáveis, o que acarreta uma super expressão dessas citocinas nesses tecidos. ${ }^{26,37-39}$ Além disso, tecidos periodontais inflamados cronicamente apresentaram um aumento na metilação do gene codificante da enzima COX-2. A produção de interleucina-1 (IL-1) é capaz de induzir a DNA metiltransferase (DNMT), provocando uma redução acentuada de vários genes, como hipoxantinaguanina fosforibosiltransferse (HPRT) ${ }^{26}$

\section{Fatores determinantes das alterações epigenéticas na doença periodontal}

A presença de lipopolissacarídeos (LPS), componente da membrana externa de bactérias Gram-negativas, pode ser um fator importante para as alterações epigenéticas no tecido periodontal. Diferentes alterações epigenéticas já foram observadas a partir da exposição de vários tipos de células à presença de LPS isolado ou bactérias lisadas. ${ }^{28}$ Em resposta à agressão bacteriana, os mecanismos de defesa do hospedeiro ativam células inflamatórias que produzem e secretam mediadores de inflamação. Isso ocorre a partir da ativação dos receptores CD14 - proteínas de membrana de macrófagos e células epiteliais capazes de detectar componentes bacterianos, como os LPS -, resultando na liberação de moléculas pró-inflamatórias como IL-1, IL-6, TNF- $\alpha$ e prostaglandinas. ${ }^{40} \mathrm{~A}$ inflamação crônica gerada pela presença das bactérias periodontopatogênicas e o acúmulo de mediadores de inflamação podem causar alterações epigenéticas. ${ }^{16,25}$ Essas alterações podem ocorrer nos genes que regulam a produção das próprias citocinas inflamatórias, aumentando a produção dessas moléculas..$^{30} \mathrm{O}$ epigenoma em si é afetado pela inflamação, entretanto as alterações epigenéticas constituem um mecanismo que medeia a produção de moléculas pró-inflamatórias incluindo a IL-1, IL-6, TNF- $\alpha$, IFN- $\gamma$, assim como a indução de produção da COX-2 e do fator nuclear kappa B

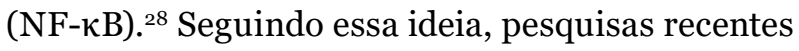
têm demonstrado que a resposta inflamatória é altamente controlada por alterações epigenéticas. ${ }^{29,35}$ Essa modulação da inflamação tem implicações em todas as doenças inflamatórias, incluindo a periodontal. ${ }^{29,41,42}$

As alterações epigenéticas nos genes codificantes de mediadores de inflamação na doença periodontal já foram associadas a estímulos ambientais, como o tabagismo e a nutrição, e às próprias bactérias orais. ${ }^{16,29,41}$ Já foi observado que o sachê de betel, um potencial carcinógeno oral, induz a inflamação e eleva a expressão de IL-6, TNF- $\alpha$ e prostaglandina E2 (PGE2) em queratinócitos do tecido gengival. ${ }^{29}$

\section{Perspectivas futuras de tratamento e prevenção por meio da epigenética na doença períodontal}

Embora estáveis, as modificações epigenéticas são reversíveis. Isso demonstra a importância do microambiente na patogênese de doenças inflamatórias. Dessa forma, o desenvolvimento de drogas epigenéticas, capazes de interferir nesse estado reversível e restaurar um ambiente "normal" quanto à produção excessiva de mediadores inflamatórios, tem gerado interesse. Apesar de ainda existirem obstáculos inerentes, as terapias epigenéticas são uma grande promessa para o tratamento de doenças de caráter inflamatório a partir de intervenções personalizadas. ${ }^{28}$

O estudo de Martins et al. ${ }^{33}$ sugere que as histonas e os receptores toll-like sejam estudados como novos focos farmacológicos para o tratamento da doença periodontal, após a descoberta de que a ativação dos receptores toll-like 1, 2 e 4 induz a acetilação das histonas. Essa reação resulta em uma maior produção de NF- $\kappa \mathrm{B}$, importante para a proteção contra infecções. Porém a ativação crônica desse 
fator nuclear leva à diferenciação dos osteoclastos e à reabsorção óssea.

Recentemente, estudos foram feitos sobre o papel das drogas inibidoras de histona deacetilases (HDCA) na remodelação óssea. Eles relataram que os inibidores de histona deacetilase (HDCAi) apresentam a capacidade de influenciar na diferenciação, maturação e atividade de osteoclastos, além de evitar a perda óssea em pacientes com artrite reumatoide e doença periodontal e, por isso, vêm sendo consideradas drogas promissoras no tratamento dessas doenças. ${ }^{43,44}$ Ademais, o tratamento dos fibroblastos do ligamento periodontal com HDCAi promoveu a expressão de proteínas relacionadas aos osteoblastos, além da inibição da superprodução de citocinas pró-inflamatórias. ${ }^{44,45}$ Relatou-se também que o inibidor da metilação do DNA 5-aza-2'-desoxicitidina (5-aza) aumentou a resposta dos fibroblastos gengivais ao fator de crescimento beta 1 (TGF- $\beta 1$ ), ${ }^{44,46}$ que são reguladores importantes no processo de cicatrização de feridas. ${ }^{46}$

\section{Alterações epigenéticas no câncer de boca}

A carcinogênese é um processo complexo em que as células envolvidas acumulam mutações em seu material genético, alterando, assim, o funcionamento da célula. Algumas dessas alterações não são modificações na sequência de DNA, e sim eventos epigenéticos. ${ }^{9}$ As alterações epigenéticas foram relatadas em casos de lesões malignas e prémalignas, sugerindo que essas alterações podem ser cruciais no início da carcinogênese oral.9,10,18

As alterações genéticas mais importantes para o desencadeamento da carcinogênese incluem a inativação de genes supressores de tumor e a ativação de oncogenes, mediados através dos eventos epigenéticos. ${ }^{16,23,47} \mathrm{Em}$ alguns tipos de câncer, observou-se a hipometilação extensa de ilhas CpG de DNA. Esse tipo de alteração pode causar a ativação de oncogenes, ativação de retrotransposição e instabilidade cromossomal. ${ }^{47}$
Os genes supressores de tumor geralmente estão relacionados com reparação do DNA, crescimento celular, inibição de ligação e metástases intracelulares, sendo ativos em células normais, porém frequentemente silenciados em células malignas. ${ }^{9}$ A inativação de genes supressores de tumor é crucial no início do desenvolvimento do carcinoma de cabeça e pescoço. ${ }^{10,47,48}$ A metilação do DNA é reconhecida como o mecanismo que causa o silenciamento dos genes supressores do tumor, como p14, p15 e p16, em alguns pacientes com carcinoma.9.47,49 Outro gene supressor de tumor importante na carcinogênese é o receptor de ácido retinóico (RAR). A supressão da função do RAR devido à metilação do gene que codifica a expressão desse receptor foi observada em $67 \%$ das amostras de câncer de cabeça e pescoço.9,50

Outro aspecto relevante é relacionado às moléculas de adesão. A E-caderina, uma glicoproteína com papel crucial na adesão entre células, está envolvida na manutenção do fenótipo epitelial e regulação da invasão tumoral. ${ }^{47} \mathrm{O}$ potencial invasivo e metastático dos carcinomas pode estar relacionado com a redução na expressão da E-caderina. A hipermetilação das ilhas CpG no gene promotor de E-caderina causa uma redução da expressão de E-caderina no tumor, tornando-o invasivo. ${ }^{47,51}$ Alguns estudos mostram que a porcentagem de metilação do gene promotor de E-caderina apresenta intervalo de 7\% a 46\% em pacientes com câncer de boca. ${ }^{9,49}$

Além destas alterações epigenéticas, é comum observar em tumores a diminuição da expressão de genes envolvidos com as vias de reparo do DNA, como o promotor de metiltransferase O-6metilguanina-DNA (MGMT). Essa enzima de reparo de DNA atua inibindo ligações cruzadas da dupla fita de DNA por meio da remoção de lesões alquilantes. A inativação desses genes devido à hipermetilação tem sido observada em casos de câncer de boca. ${ }^{9,47,49}$

De tal modo, a hipermetilação de promotores de genes envolvidos na apoptose, como p73, 
proteína quinase associada a morte da célula, e RASSF2, também pode ser observada durante a carcinogênese. ${ }^{47} \mathrm{O}$ gene supressor de tumor que regula a expressão da proteína DAP quinase, que está implicada na apoptose e inibe potencialmente o aparecimento de metástases, foi observado na saliva, como um gene hipermetilado, em $18 \%$ a $60 \%$ dos pacientes com câncer de cabeça e pescoço. ${ }^{9}$

O ponto de verificação com os domínios Fork-head e Ring finger (CHFR) funciona como uma proteína importante no ponto de checagem no início da transcrição. A taxa de metilação do gene promotor de CHFR é muito menor em mucosas saudáveis que em mucosas com células cancerígenas. ${ }^{48}$

\section{Fatores determinantes das alterações epigenéticas no câncer}

Vários estudos demonstram que a inflamação crônica pode ser um fator importante no desenvolvimento e na progressão do câncer através da indução de alterações epigenéticas. ${ }^{16,52}$ Infecção e inflamação constituem aproximadamente 25\% dos fatores causais de todos os tipos de câncer. ${ }^{13} \mathrm{~A}$ ligação entre a inflamação crônica e o câncer foi inicialmente descrita, no século XIX, por Rudolf Virchow que observou que os tumores frequentemente apresentam infiltrados de células imunológicas..$^{52}$

As quimiocinas, citocinas, prostaglandinas e outros mediadores de inflamação produzidos no processo de inflamação crônica se acumulam no local afetado e, quando persistentes, apresentam a capacidade de promover a sobrevivência de células e induzir a proliferação celular mediante a ativação de oncogenes e a inibição de genes supressores de tumor por meio de alterações epigenéticas. ${ }^{12,16,18}$ Por exemplo, observou-se que no câncer gástrico desencadeado a partir de uma infecção inicial por Helicobacter pylori, a produção de IL-1b aumenta a atividade da enzima DNMT, responsável pelo processo de metilação do DNA, ocasionando silenciamento gênico do gene $\mathrm{CDH} 1$, que codifica a E-caderina. ${ }^{12}$ A presença persistente da citocina inflamatória IL-6 induz a atividade da enzima DNMT1, resultando na metilação do DNA de genes supressores de tumor e, consequentemente, no silenciamento desses genes..$^{2}$

Alguns fatores de transcrição específicos têm a capacidade de regular tanto a produção de mediadores de inflamação quanto a proliferação e sobrevivência de células malignas. Dessa forma, esses fatores de transcrição comuns podem ser uma ligação entre o câncer e a inflamação crônica. ${ }^{12,15,23}$

Agentes inflamatórios, tabaco e álcool têm a capacidade de ativar fatores de transcrição como o transdutor de sinal e ativador da transcrição 3 (STAT-3), proteína ativadora 1 (AP-1) e NF- $\kappa \mathrm{B}$, que por sua vez podem ativar oncogenes que regularão a apoptose e a proliferação celular e de genes reguladores da produção dos mediadores de inflamação como citocinas, fatores de crescimento e prostaglandinas. ${ }^{12}$

\section{Perspectivas futuras de tratamento e prevenção através da epigenética no câncer de boca}

Como as mudanças epigenéticas são potencialmente reversíveis, novas oportunidades para o manejo clínico do câncer podem ser pensadas. $\mathrm{O}$ desenvolvimento de mecanismos capazes de reverter as alterações epigenéticas e, como consequência, o silenciamento ou a ativação dos genes deverá ser estudado para fins de prevenção e tratamento de doenças neoplásicas. ${ }^{18,22,53}$

Os HDACis podem ser usados como agentes antitumorais altamente seletivos, apresentando atividade significativa em várias neoplasias humanas, incluindo o carcinoma de células escamosas oral. Os HDACis são capazes de parar o ciclo celular e induzir a apoptose de células malignas. Os dados conhecidos atualmente sobre os HDACis podem fornecer novas opções terapêuticas para os carcinomas de células 
escamosas oral, permitindo a redução dos efeitos colaterais do tratamento a partir de uma terapia mais conservadora. Entretanto, ainda são necessários estudos focados na atividade dos HDACis in vivo e na sua avaliação clínica como agentes terapêuticos isolados ou em combinação com outros métodos. ${ }^{23,54}$

Algumas drogas epigenéticas inibidoras de DNMT têm sido avaliadas em estudos e pré-clínicos de outros tipos de câncer, como o câncer gástrico. Dentre esses fármacos, o Zebularine mostrou ser capaz de reduzir a hipermetilação de genes supressores tumorais, ${ }^{23}$ como o p16, em várias linhagens de células cancerígenas, inibindo a proliferação de células de câncer gástrico e induzindo a apoptose. ${ }^{55,56}$

As alterações epigenéticas associadas ao silenciamento e ativação de genes ligados à carcinogênese podem servir de marcadores moleculares para obtenção do diagnóstico, prognóstico e avaliação do risco do câncer. A detecção de ilhas $\mathrm{CpG}$ com alterações de metilação como biomarcadores de câncer pode ser conseguida através da utilização do método de polimerase em cadeia (PCR). ${ }^{53}$

\section{Inter-relação entre a doença periodontal e o câncer de boca}

Estudos prévios de revisão sistemática e metaanálise concluíram que existe uma relação positiva entre essas duas doenças. Os resultados indicaram que a doença periodontal pode aumentar o risco de câncer bucal. ${ }^{19}$ Após o ajuste de fatores de confusão, como o tabagismo, etilismo, idade e sexo, a doença periodontal foi considerada um fator de risco independente para o câncer bucal.,36,17

O estudo retrospectivo de caso controle feito por Moergel et al. ${ }^{2}$ confirmou que a presença de perda óssea alveolar constitui um fator de risco independente para o desenvolvimento de carcinoma oral de células escamosas. A Tabela 1 demonstra o resultado dos principais estudos sobre a inter-relação entre doença periodontal e câncer de boca.

TABELA 1 | Estudos científicos sobre a inter-relação entre a doença periodontal e o câncer de boca.

\begin{tabular}{c|c|c|c|c|}
\hline Autores & Ano & Tipo de estudo & Resultado \\
\hline Moergel et al. ${ }^{2}$ & 2013 & Caso-controle & $\begin{array}{r}\text { Perda óssea alveolar é um fator de risco para o câncer de boca } \\
{[\text { OR }=2,4 ; \text { IC 95\% }(1,5-3,8) ; p<0,001] .}\end{array}$ \\
\hline Javed e Warnakulasuriya ${ }^{17}$ & 2016 & Revisão sistemática & A doença periodontal está associada a um aumento do risco \\
de câncer de boca
\end{tabular}

IC: intervalo de confiança; OR: odds ratio; p: probabilidade de significância.

\section{DISCUSSÃO}

Os resultados desta revisão narrativa sobre as alterações epigenéticas no câncer de boca e na doença periodontal alertam para a importante plausibilidade biológica entre essas condições. Além disso, abrem a perspectiva de futuras pesquisas que comprovem a impactante inter-relação entre ambas.

A doença periodontal é capaz de induzir alterações na expressão gênica de forma crônica e persistente ${ }^{30,31}$, sendo plausível afirmar o seu potencial de influenciar no risco de desenvolvimento e progressão tumoral. Em uma em cada quatro manifestações da doença, verificase a presença da inflamação crônica, considerada um fator de risco importante para o câncer em geral. ${ }^{20,23}$

A constante produção de quimiocinas, citocinas, fatores de crescimento, dentre outros mediadores de inflamação, criam um ambiente favorável ao acúmulo de alterações gênicas em células epiteliais. ${ }^{14,16,18,20}$ Estas alterações epigenéticas ativam oncogenes e inibem genes supressores de tumor. ${ }^{12,16,18}$ 
As evidências reforçam a ideia de que a infecção por microrganismos periodontopatogênicos desencadeia uma resposta inflamatória aguda e crônica. A manutenção deste estado inflamatório pode induzir alterações epigenéticas relacionadas ao surgimento de carcinoma de células escamosas. ${ }^{18}$ Os mediadores inflamatórios envolvidos na doença periodontal mostraram ter potencial para transformação maligna in vitro. ${ }^{2}$

Um exemplo de citocina inflamatória importante no processo de progressão da periodontite e na metilação de genes são as interleucinas (IL). ${ }^{16,57}$ Estas citocinas pró-inflamatórias são capazes de alterar o padrão de metilação de genes supressores de tumor através da hipermetilação, impedindo, dessa forma, a expressão desses genes. ${ }^{16,20}$ Outra importante ação das IL na epigenética do câncer é sua capacidade de modular a expressão dos genes envolvidos na apoptose e no ciclo celular. ${ }^{14,16}$

Outro aspecto abordado sobre a plausibilidade biológica entre a doença periodontal e o câncer é relacionado ao fator de transcrição NF-кB. Esse fator de transcrição desempenha um papel prócarcinógeno em células epiteliais, ${ }^{11}$ sendo essencial na ativação de numerosas citocinas pró-inflamatórias. $\mathrm{O}$ gene codificante de NF- $\kappa$ B é hipometilado em células epiteliais gengivais de pacientes com periodontite sendo que esse padrão de metilação não é observado em células gengivais de pacientes saudáveis. Portanto, a expressão de NF- $\kappa$ B é maior em tecidos periodontais inflamados. ${ }^{32,34,37}$ Nesse contexto, o aumento da expressão de IL mediado por NF- $\kappa$ B poderia promover a tumorigênese. ${ }^{11}$

É importante salientar que o tabagismo também causa hipometilação e hipermetilação no DNA. ${ }^{25} \mathrm{~A}$ metilação do p16 e E-caderina no câncer de boca parece estar relacionada com o hábito de tabagismo, uma vez que a exposição ao tabaco induz direta ou indiretamente danos às ilhas $\mathrm{CpG}$ em determinados genes. ${ }^{9} \mathrm{O}$ tabagismo, incluindo o consumo de sachê de betel, também é capaz de modificar o padrão de metilação dos genes codificantes de mediadores de inflamação na periodontite. ${ }^{29}$ Ressalta-se que o hábito de tabagismo consiste em um fator de risco para a doença periodontal e para o câncer de boca. ${ }^{4,16,19}$

As drogas epigenéticas são uma esperança futura no tratamento de doenças inflamatórias, incluindo a doença periodontal e o câncer, devido ao caráter potencialmente reversível das alterações epigenéticas. ${ }^{23,38}$ Fármacos inibidores de HDCA já apresentaram efeitos positivos no tratamento de fibroblastos periodontais, ${ }^{43,44}$ dentre eles, a inibição da produção excessiva de citocinas próinflamatórias. ${ }^{43,45}$ Os HDACis também estão sendo estudados no tratamento do câncer, pois apresentam a capacidade de induzir a apoptose de células malignas, além de paralisar o ciclo celular, sendo altamente seletivos para células tumorais. ${ }^{54}$ Outras drogas epigenéticas que vêm sendo desenvolvidas são os inibidores de DNMT,44,46,55,56 capazes de reduzir a hipermetilação de genes supressores tumorais, induzindo a apoptose e a supressão da proliferação de células malignas. ${ }^{55,56} \mathrm{Na}$ doença periodontal, os DNMTis podem ser úteis, pois aumentam a resposta dos fibroblastos gengivais ao TGF- $\beta 1$, importante fator de crescimento relacionado à cicatrização. ${ }^{44,46}$

Adicionalmente, uma importante associação entre a doença periodontal e o câncer de boca tem sido demonstrada em vários estudos clínicos e de revisão. Os resultados dessas pesquisas científicas demonstram que a doença periodontal pode aumentar o risco de desenvolvimento de câncer de boca. ${ }^{2,3,16-18,23}$

Embora a compreensão da influência dos mecanismos epigenéticos na odontologia ainda esteja em sua fase inicial, já se sabe que eles apresentam grande importância no desenvolvimento de alterações patológicas na cavidade bucal. ${ }^{1}$ Estas alterações epigenéticas podem ajudar a explicar a plausibilidade biológica entre a doença periodontal e o câncer de boca. Assim, as evidências científicas aqui reunidas sobre modificações epigenéticas na doença periodontal e no câncer de boca, sugerem uma 
correlação positiva entre as duas doenças, indicando que as alterações epigenéticas desencadeadas no processo de adoecimento periodontal podem ser um importante fator de risco para o desenvolvimento do câncer de boca.

\section{CONCLUSÃO}

Os dados dos estudos científicos analisados demonstraram que as periodontopatias caracterizadas por inflamação crônica induzida por bactérias específicas que compõem o biofilme dental, são capazes de produzir modificações epigenéticas importantes capazes de ativar oncogenes e inibir genes supressores de tumor. As principais alterações epigenéticas estão relacionadas à metilação do DNA e modificações de histonas, que contribuem para o desenvolvimento e a progressão do câncer de boca. Logo, as evidências apontam para uma relação positiva entre essas duas doenças, sugerindo que as modificaçoes epigenéticas desencadeadas na doença periodontal podem representar um potencial fator de risco para o câncer de boca.

\section{REFERÊNCIAS}

1. Ari G, Cherukuri S, Namasivayam A. Epigenetics and Periodontitis: A Contemporary Review. J Clin Diagn Res. 2016;10(11):ZE07-9. Doi: https://doi.org/10.786o/ JCDR/2016/21025.8864

2. Moergel M, Kämmerer P, Kasaj A, Armouti E, Alshihri A, Weyer V, et al. Chronic periodontitis and its possible association with oral squamous cell carcinoma - a retrospective case control study. Head Face Med. 2013;9:39. Doi: https:// doi.org/10.1186/1746-16oX-9-39

3. Yao QW, Zhou DS, Peng HJ, Ji P, Liu DS. Association of periodontal disease with oral cancer: a meta-analysis. Tumour Biol. 2014;35(7):7073-7. Doi: https://doi.org/10.1007/s13277014-1951-8

4. Michaud DS, Fu Z, Shi J, Chung M. Periodontal Disease, Tooth Loss, and Cancer Risk. Epidemiol Rev. 2017;39(1):4958. Doi: https://doi.org/10.1093/epirev/mxxoo6

5. Fabri GM, Siqueira SR, Simione C, Nasri C, Teixeira MJ, Siqueira JT. Refractory craniofacial pain: is there a role of periodontal disease as a comorbidity? Arq Neuropsiquiatr. 2009;67(2B):474-9. Doi: https://doi.org/10.159o/sooo4282x2009000300018

6. Fabri GM, Pereira RM, Savioli C, Saad CG, Moraes JC, Siqueira JT, et al. Periodontitis Response to Anti-TNF Therapy in Ankylosing Spondylitis. J Clin Rheumatol. 2015;21(7):341-5. Doi: https://doi.org/10.1097/RHU.ooooooooooooo300

7. Fabri GMC. Potential Link between COVID-19 and Periodontitis: Cytokine Storm, Immunosuppression, and Dysbiosis. Oral Health Dent Manag. 2020;20(1):1-5.

8. Instituto Nacional de Câncer José Alencar Gomes da Silva. Estimativa 2020: incidência de câncer no Brasil. Rio de Janeiro: INCA; 2019.

9. Díez-Pérez R, Campo-Trapero J, Cano-Sánchez J, LópezDurán M, Gonzalez-Moles MA, Bascones-Ilundain J, et al. Methylation in oral cancer and pre-cancerous lesions (Review). Oncol Rep. 2011;25(5):1203-9. Doi: https://doi. org/10.3892/or.2011.1205

10. Ha PK, Califano JA. Promoter methylation and inactivation of tumour-suppressor genes in oral squamous-cell carcinoma. Lancet Oncol. 2006;7(1):77-82. Doi: https://doi.org/10.1016/ S1470-2045(05)70540-4

11. Bromberg J, Wang TC. Inflammation and cancer: IL-6 and STAT3 complete the link. Cancer Cell. 2009;15(2):79-80. Doi: https://doi.org/10.1016/j.ccr.2009.01.009

12. Feller L, Altini M, Lemmer J. Inflammation in the context of oral cancer. Oral Oncol. 2013;49(9):887-92. Doi: https:// doi.org/10.1016/j.oraloncology.2013.07.003

13. Murata M. Inflammation and cancer. Environ Health Prev Med. 2018;23(1):50. Doi: https://doi.org/10.1186/s12199-0180740-1

14. Kundu JK, Surh YJ. Inflammation: gearing the journey to cancer. Mutat Res. 2008;659(1-2):15-30. Doi: https://doi. org/10.1016/j.mrrev.2008.03.002

15. Moore MM, Chua W, Charles KA, Clarke SJ. Inflammation and cancer: causes and consequences. Clin Pharmacol Ther. 2010;87(4):504-8. Doi: https://doi.org/10.1038/ clpt.2009.254

16. Barros SP, Fahimipour F, Tarran R, Kim S, Scarel-Caminaga $\mathrm{RM}$, Justice A, et al. Epigenetic reprogramming in periodontal disease: Dynamic crosstalk with potential impact in oncogenesis. Periodontol 2000. 2020;82(1):157-72. Doi: https:// doi.org/10.1111/prd.12322

17. Javed F, Warnakulasuriya S. Is there a relationship between periodontal disease and oral cancer? A systematic review of currently available evidence. Crit Rev Oncol Hematol. 
2016;97:197-205. Doi: https://doi.org/10.1016/j.critrevonc.2015.08.018

18. Li S, Liu X, Zhou Y, Acharya A, Savkovic V, Xu C, et al. Shared genetic and epigenetic mechanisms between chronic periodontitis and oral squamous cell carcinoma. Oral Oncol. 2018;86:216-24. Doi: https://doi.org/10.1016/j.oraloncology.2018.09.029

19. Ye L, Jiang Y, Liu W, Tao H. Correlation between periodontal disease and oral cancer risk: A meta-analysis. J Cancer Res Ther. 2016;12(Suppl):C237-40. Doi: https://doi. org/10.4103/0973-1482.200746

20. Stuani VT, Sant'Ana ACP, Soares LAV Jr, Santos PSS. A relação entre doença periodontal e o câncer oral. Rev Bras Odontol. 2016;73(3):218-22.

21. Saleh R, Toor SM, Sasidharan Nair V, Elkord E. Role of Epigenetic Modifications in Inhibitory Immune Checkpoints in Cancer Development and Progression. Front Immunol. 2020;11:1469. Doi: https://doi.org/10.3389/fimmu.2020.01469

22. Adcock IM, Tsaprouni L, Bhavsar P, Ito K. Epigenetic regulation of airway inflammation. Curr Opin Immunol. 2007;19(6):694-700. Doi: https://doi.org/10.1016/j. coi.2007.07.016

23. Irimie AI, Ciocan C, Gulei D, Mehterov N, Atanasov AG, Dudea D, et al. Current Insights into Oral Cancer Epigenetics. Int J Mol Sci. 2018;19(3):670. Doi: https://doi.org/10.3390/ ijms19030670

24. Khouly I, Braun RS, Ordway M, Aouizerat BE, Ghassib I, Larsson L, et al. The Role of DNA Methylation and Histone Modification in Periodontal Disease: A Systematic Review. Int J Mol Sci. 2020;21(17):6217. Doi: https://doi.org/10.3390/ ijms21176217

25. Seo JY, Park YJ, Yi YA, Hwang JY, Lee IB, Cho BH, et al. Epigenetics: general characteristics and implications for oral health. Restor Dent Endod. 2015;40(1):14-22. Doi: https:// doi.org/10.5395/rde.2015.40.1.14

26. Gomez RS, Dutra WO, Moreira PR. Epigenetics and periodontal disease: future perspectives. Inflamm Res. 2009;58(10):625-9. Doi: https://doi.org/10.1007/sooo11009-0041-7

27. Dhanuthai K, Rojanawatsirivej S, Thosaporn W, Kintarak S, Subarnbhesaj A, Darling M, et al. Oral cancer: A multicenter study. Med Oral Patol Oral Cir Bucal. 2018;23(1):e23-9. Doi: https://doi.org/10.4317/medoral.21999

28. Barros SP, Hefni E, Nepomuceno R, Offenbacher S, North $\mathrm{K}$. Targeting epigenetic mechanisms in periodontal diseas- es. Periodontol 200o. 2018;78(1):174-84. Doi: https://doi. org/10.1111/prd.12231

29. Williams SD, Hughes TE, Adler CJ, Brook AH, Townsend GC. Epigenetics: a new frontier in dentistry. Aust Dent J. 2014;59(1 Suppl):23-33. Doi: https://doi.org/10.1111/adj.12155

30. Barros SP, Offenbacher S. Modifiable risk factors in periodontal disease: epigenetic regulation of gene expression in the inflammatory response. Periodontol 2000. 2014;64(1):95110. Doi: https://doi.org/10.1111/prd.1200o

31. Bobetsis YA, Barros SP, Lin DM, Weidman JR, Dolinoy DC, Jirtle RL, et al. Bacterial infection promotes DNA hypermethylation. J Dent Res. 2007;86(2):169-74. Doi: https:// doi.org/10.1177/154405910708600212

32. Zhang S, Barros SP, Niculescu MD, Moretti AJ, Preisser JS, Offenbacher S. Alteration of PTGS2 promoter methylation in chronic periodontitis. J Dent Res. 2010;89(2):133-7. Doi: https://doi.org/10.1177/0022034509356512

33. Martins MD, Jiao Y, Larsson L, Almeida LO, Garaicoa-Pazmino C, Le JM, et al. Epigenetic Modifications of Histones in Periodontal Disease. J Dent Res. 2016;95(2):215-22. Doi: https://doi.org/10.1177/0022034515611876

34. Offenbacher S, Barros SP, Singer RE, Moss K, Williams RC, Beck JD. Periodontal disease at the biofilm-gingival interface. J Periodontol. 2007;78(10):1911-25. Doi: https://doi. org/10.1902/jop.2007.060465

35. Zhang S, Barros SP, Moretti AJ, Yu N, Zhou J, Preisser JS, et al. Epigenetic regulation of TNFA expression in periodontal disease. J Periodontol. 2013;84(11):1606-16. Doi: https://doi. org/10.1902/jop.2013.120294

36. Duarte PM, Rocha M, Sampaio E, Mestnik MJ, Feres M, Figueiredo LC, et al. Serum levels of cytokines in subjects with generalized chronic and aggressive periodontitis before and after non-surgical periodontal therapy: a pilot study. J Periodontol. 2010;81(7):1056-63. Doi: https://doi. org/10.1902/jop.2010.090732

37. Andia DC, Oliveira NF, Casarin RC, Casati MZ, Line SR, Souza AP. DNA methylation status of the IL8 gene promoter in aggressive periodontitis. J Periodontol. 2010;81(9):133641. Doi: https://doi.org/10.1902/jop.2010.100082

38. Offenbacher S, Barros SP, Beck JD. Rethinking periodontal inflammation. J Periodontol. 2008;79(8 Suppl):1577-84. Doi: https://doi.org/10.1902/jop.2008.080220

39. Zhang S, Crivello A, Offenbacher S, Moretti A, Paquette DW, Barros SP. Interferon-gamma promoter hypomethylation and increased expression in chronic periodontitis. J Clin 
Periodontol. 2010;37(11):953-61. Doi: https://doi.org/10.1111/ j.1600-051X.2010.01616.x

40. Bascones-Martínez A, Muñoz-Corcuera M, Noronha S, Mota P, Bascones-Ilundain C, Campo-Trapero J. Host defence mechanisms against bacterial aggression in periodontal disease: Basic mechanisms. Med Oral Patol Oral Cir Bucal. 2009;14(12):e68o5. Doi: https://doi.org/10.4317/medoral.14.e680

41. Loos BG, Van Dyke TE. The role of inflammation and genetics in periodontal disease. Periodontol 2000. 2020;83(1):26-39. Doi: https://doi.org/10.1111/prd.12297

42. Martino DJ, Prescott SL. Silent mysteries: epigenetic paradigms could hold the key to conquering the epidemic of allergy and immune disease. Allergy. 2010;65(1):7-15. Doi: https://doi.org/10.1111/j.1398-9995.2009.02186.x

43. Cantley MD, Bartold PM, Marino V, Fairlie DP, Le GT, Lucke AJ, et al. Histone deacetylase inhibitors and periodontal bone loss. J Periodontal Res. 2011;46(6):697-703. Doi: https://doi. org/10.1111/j.1600-0765.2011.01392.x

44. Larsson L. Current Concepts of Epigenetics and Its Role in Periodontitis. Curr Oral Health Rep. 2017;4(4):286-93. Doi: https://doi.org/10.1007/s40496-017-0156-9

45. Kim TI, Han JE, Jung HM, Oh JH, Woo KM. Analysis of histone deacetylase inhibitor-induced responses in human periodontal ligament fibroblasts. Biotechnol Lett. 2013;35(1):12933. Doi: https://doi.org/10.1007/s10529-012-0992-6

46. Sufaru IG, Beikircher G, Weinhaeusel A, Gruber R. Inhibitors of DNA methylation support TGF- $\beta 1$-indiced IL11 expression in gingival fibroblasts. J Periodontal Implant Sci. 2017;47(2):6676. Doi: https://doi.org/10.5051/jpis.2017.47.2.66

47. Radhakrishnan R, Kabekkodu S, Satyamoorthy K. DNA hypermethylation as an epigenetic mark for oral cancer diagnosis. J Oral Pathol Med. 2011;40(9):665-76. Doi: https://doi. org/10.1111/j.1600-0714.2011.01055.x

48. Baba S, Hara A, Kato K, Long NK, Hatano Y, Kimura M, et al. Aberrant promoter hypermethylation of the CHFR gene in oral squamous cell carcinomas. Oncol Rep. 2009;22(5):11739. Doi: https://doi.org/10.3892/or_ooooo552
49. Viet CT, Jordan RC, Schmidt BL. DNA promoter hypermethylation in saliva for the early diagnosis of oral cancer. J Calif Dent Assoc. 2007;35(12):844-9.

50. Youssef EM, Lotan D, Issa JP, Wakasa K, Fan YH, Mao L, et al. Hypermethylation of the retinoic acid receptor-beta(2) gene in head and neck carcinogenesis. Clin Cancer Res. 2004;10(5):1733-42. Doi: https://doi.org/10.1158/1078-0432. ccr-0989-3

51. Kudo Y, Kitajima S, Ogawa I, Hiraoka M, Sargolzaei S, Keikhaee MR, et al. Invasion and metastasis of oral cancer cells require methylation of E-cadherin and/or degradation of membranous beta-catenin. Clin Cancer Res. 2004;10(16):5455-63. Doi: https://doi.org/10.1158/10780432.CCR-04-0372

52. Rokavec M, Öner MG, Hermeking H. Inflammation-induced epigenetic switches in cancer. Cell Mol Life Sci. 2016;73(1):2339. Doi: https://doi.org/10.1007/sooo18-015-2045-5

53. HermanJG, Baylin SB. Genesilencing in cancer in association with promoter hypermethylation. N Engl J Med. 2003;349(21):204254. Doi: https://doi.org/10.1056/NEJMra023075

54. Tasoulas J, Giaginis C, Patsouris E, Manolis E, Theocharis S. Histone deacetylase inhibitors in oral squamous cell carcinoma treatment. Expert Opin Investig Drugs. 2015;24(1):6978. Doi: https://doi.org/10.1517/13543784.2014.952368

55. Tan W, Zhou W, Yu HG, Luo HS, Shen L. The DNA methyltransferase inhibitor zebularine induces mitochondriamediated apoptosis in gastric cancer cells in vitro and in vivo. Biochem Biophys Res Commun. 2013;430(1):250-5. Doi: https://doi.org/10.1016/j.bbrc.2012.10.143

56. Zeng XQ, Wang J, Chen SY. Methylation modification in gastric cancer and approaches to targeted epigenetic therapy (Review). Int J Oncol. 2017;50(6):1921-33. Doi: https://doi. org/10.3892/ijo.2017.3981

57. Tâlvan ET, Mohor C, Chisnoiu D, Cristea V, Câmpian RS. Expression of interleukin (IL)-1 $\beta$, IL-8, IL-10 and IL-13 in Chronic Adult Periodontitis Progression. Arch Med (Oviedo). 2017;9(3):4. 